\title{
BASE TEÓRICA PARA ESTUDOS EXPLORATÓRIOS DA EXPERIÊNCIA CONSCIENTE DA VIOLÊNCIA PSICOLÓGICA
}

\author{
Theoretical Basis for Exploratory Studies of Conscious Experience of Psychological Violence
}

\author{
Base Teórica para Estudios Exploratorios de la Experiéncia Consciente de la \\ Violéncia Psicológica
}

Adelma Pimentel

PaOlo Mindello

\begin{abstract}
Resumo: Este artigo examina textos que abordam a concepção de consciência para analisar relações entre experiência consciente e violência psicológica em contexto familiar visando intervenções preventivas que permitam rever os vínculos familiares e a sociabilidade pública. Na lógica interna da violência psicológica estão estabelecidas práticas irracionais, em consequência, os atores que a vivenciam não transparecem a consciência da existência do outro e/ou de si mesmo. Na pesquisa, o procedimento interpretativo e metodológico foi à investigação bibliográfica: leituras, fichamentos e análises dos textos. A estrutura da escritura é constituída pela exposição de alguns modos que a consciência é pensada por várias ciências, teses gestálticas e pela apresentação do pensamento de alguns autores sobre violência psicológica que ocorre nas famílias. À guisa de conclusão ponderamos que, na literatura focalizada as dificuldades conceituais permanecem, isto é, as neurociências, a psicologia cognitiva, a análise do comportamento e a psiquiatria não têm ferramentas metodológicas para responder precisamente o que é a consciência; assim, nos afastamos da querela metodológica e elegemos algumas cogitações gestálticas e da fenomenologia existencial heideggeriana para analisar possíveis relações entre experiência consciente e violência psicológica.
\end{abstract}

Palavras-chave: Consciência; Violência Psicológica; Pesquisa Qualitativa.

Abstract: This article examines texts that discuss the concept of consciousness to analyze relationship between conscious experience and psychological violence in the family context in order to preventive interventions that allow family ties to revise the public sociability. In the internal logic of psychological violence are established practices irrational thoughts, as a result, the actors who experience it does not transpire awareness of the existence of another and / or of oneself. In the survey, the procedure was interpretive and methodological research literature: readings, reviews and analysis of texts. The structure consists of writing the exposure of some ways that consciousness is thought by many sciences, theses gestalt of thought and presentation of some authors about psychological violence that occurs in families. As a conclusion we ponder that, in the literature focused on the conceptual difficulties remain, neuroscience, cognitive psychology, behavior analysis and psychiatry have methodological tools to answer precisely what is consciousness, so we move away from complaint methodological and elect some musings gestalt and existential Heideggerian phenomenology to analyze possible relationships between conscious experience and psychological violence

Keywords: Consciousness; Psychological Violence; Qualitative Research.

Resumen: Este artículo examina los textos que tratan sobre el concepto de la conciencia para analizar la relación entre la experiencia consciente y la violencia psicológica en el contexto de la familia a fin de generar intervenciones preventivas que permitan a los lazos familiares para revisar la sociabilidad pública. En la lógica interna de la violencia psicológica se establecen los pensamientos irracionales.. En la encuesta, el procedimiento fue la literatura de investigación interpretativa y metodológica: lecturas, fichamentos y análisis de textos. La estructura consiste en escribir la exposición de algunas formas en que la conciencia es considerado por muchas ciencias, tesis gestalt del pensamiento y la presentación de algunos autores sobre la violencia psicológica que se produce en las familias. Como conclusión a la que ponderar que, en la literatura se centró en las dificultades conceptuales siguen siendo, es decir, la neurociencia, la psicología cognitiva, el análisis del comportamiento y la psiquiatría tienen herramientas metodológicas para responder con precisión qué es la conciencia, por lo que nos alejamos de la demanda metodológica y elegirán a uno gestalt reflexiones de Heidegger y la fenomenología existencial para analizar las posibles relaciones entre la experiencia consciente y la violencia psicológica

Palabras-clave: Conciencia; Violencia Psicológica; Investigación Cualitativa. 


\section{Introdução}

A consciência intencional é um pressuposto que fundamenta a teorização e a intervenção clínica da Gestalt-terapia (Perls, 1942/1975; Perls, Hefferline \& Goodman, 1951/1997). A violência doméstica ou intrafamiliar, praticada por agentes consanguíneos, é uma denominação usual na literatura científica para abordar as ações de maus tratos, abuso, negligência, omissão, opressão, etc. que ocorrem nas famílias. (Pimentel \& Moreira, 2008; Pimentel \& Araújo, 2009; Pimentel, 2011). Neste texto, abordamos uma interlocução entre a experiência consciente e a violência psicológica que ocorre nas famílias, preparando a base teórica para futuras análises de material empírico coletado em pesquisas qualitativas.

A consciência da violência praticada e vivenciada; a demarcação de fronteiras entre a agressividade, a agressão e a violência; definições mais precisas da violência psicológica que ocorre na família; as possíveis relações entre experiência consciente e violência psicológica e suas repercussões no autoconceito de homens e de mulheres, são questões gerais orientadoras das nossas pesquisas $^{1}$ na graduação, iniciação científica e no programa de mestrado em psicologia da Universidade Federal do Pará desde o ano de 2005.

No contexto pós-moderno caracterizado pela impermanência, instabilidade, rapidez, novas formas de conjugalidade e organização familiar ${ }^{2}$, nossos estudos empíricos indagam, através de pesquisa qualitativa exploratória, o exame de possíveis relações entre experiência consciente e violência psicológica. Justificamos a elaboração deste artigo tendo em vista contribuir para a clarificação do campo conceitual da violência que ocorre nas famílias, pois, identificamos nos documentos pesquisados uma grande variedade de códigos linguísticos e imprecisão conceitual; por exemplo, os autores se valem igualmente da categoria violência doméstica e da violência intrafamiliar para abordar as formas de violências (Neves \& Romanelli, 2006; Saliba, Garbin, Garbin, \& Dossi, 2007; Silva \& Oliveira, 2008; Porto, 2008).

O procedimento interpretativo e metodológico para abordagem do assunto se deu por meio da pesquisa bibliográfica (Salvador, 1978; Brad, 1999). Após leituras, fichamentos e análises dos textos, desenhamos um quadro teórico que servirá de referência para dialogar e dar sustentação a análise conceitual posterior das pesquisas empíricas.

\footnotetext{
Núcleo de Pesquisas Fenomenológicas (NUFEN), Universidade Federal do Pará.

2 Vale destacar que os estudos da família são dialéticos, ou seja, estudados interdisciplinarmente e vinculados transversalmente às políticas sociais, de saúde e de trabalho definidas pelas instâncias municipais, estaduais e federais.
}

\section{Delimitando o Campo: Experiência Consciente e Violência Privada}

Santos e Sougey (2008) afirmam que,

Existem diversas classificações, concepções e definições de consciência. Natsoulas assinala as diferentes concepções usadas para designar a consciência. Armstrong distingue os três sentidos da palavra consciência. Tulving propõe três tipos de consciência. Farting estabelece distinção entre consciências partindo de suas funções primárias e secundárias. Block, enfatizando o aspecto fenomenológico da questão, propõe distinção entre consciência fenomenal e consciência de acesso. Damásio propõe dois tipos de consciência relacionados a dois tipos de self: consciência central vinculada a um self central, e consciência amplificada, de natureza complexa, que permite uma espécie de reatualização de vivências relativas à estrutura do self (p. 48).

Acerca da questão conceitual e teórica da consciência, as abordagens se dão pela psiquiatria, filosofia, neurologia, psicologia, etc. Conforme Teixeira (2011) há o reaparecimento de uma preocupação crescente com a questão da natureza da consciência, cujos marcos são os estudos de Jackendoff, Calvin, Dennett e Flanagan, situando-a, no âmbito de teorias cognitivistas e no âmbito das neurociências.

Tourinho (2002) faz a resenha do livro de Searle publicado em 1998 pela editora Paz e Terra, ilustrando as polêmicas principais neste trecho:

Dentre os temas abordados na Filosofia da Mente contemporânea, nota-se, nas últimas décadas, um interesse cada vez maior pelos debates concernentes à noção de consciência. Discute-se, sobretudo, com o avanço dos programas de pesquisa advindos da Neurociência e da Inteligência Artificial, a possibilidade de inserção dos estudos sobre a mente consciente no campo do saber científico. No entanto, as teorias que habitam a área da Filosofia da Mente parecem estar longe de chegar a um consenso quanto ao tema em questão. Afinal de contas, até que ponto, poderíamos fornecer uma explicação científica para o domínio consciente dos estados mentais? Em termos mais precisos, estaríamos confinados a conceber a consciência como uma propriedade irredutivelmente subjetiva, não-analisável, indecomponível (não relacional), que faz com que os estados de consciência sejam, de maneira privilegiada, acessíveis apenas para o próprio sujeito, do ponto de vista da primeira pessoa? Ou estaríamos diante de um fenômeno que pode ser objetivado, passível de receber uma definição e uma explicação causal, necessariamente formulada na terceira pessoa? (p. 182). 
Carvalho Neto, Alves e Baptista (2007, p. 28) analisam que a violência é um problema comportamental complexo e criticam as abordagens mentalistas da consciência que orientam a elaboração de algumas políticas públicas:

(...) Nesse modo de pensar mentalista, a violência é explicada pela ausência de uma suposta força motriz moral interna, chamada consciência, que regularia as ações humanas, direcionando-as para o bem comum. Na sua ausência, prevaleceria um padrão egoísta que resultaria em crimes.

Consideramos que além das dificuldades teóricas, as neurociências, a psicologia cognitiva, a análise do comportamento e a psiquiatria não têm ferramentas metodológicas para responder precisamente o que é a consciência. Portanto, nos afastamos da querela metodológica e elegemos as reflexões gestálticas e algumas da fenomenologia existencial heideggeriana para pensar possíveis relações entre experiência consciente da violência psicológica ressaltando o aspecto relacional da existência com os outros (Heidegger, 1997)

No sistema teórico elaborado por Perls (1942/1975, p. 182) há uma diferença entre os construtos consciência e a ideais. No primeiro há uma formação fundo/ figura; enquanto no segundo, há uma formação figura/ fundo. $\mathrm{O}$ autor considera que,

A experiência consciente é determinada pela consciência, pelos ideais e pelo id, sem um fácil reconhecimento subjetivo do processo. A integração subjetiva pode ser alcançada por meio do sentimento de identificação do eu com alguma coisa. Tal processo é realizado pelas funções do ego (Perls, 1942/1975, p. 182).

Consciência, então é a capacidade perceptiva de identificar e reconhecer a si mesmo, o contexto e o outro. Polster e Polster (1979) afirmam que na clínica gestáltica, a intervenção terapêutica é dirigida para o descontrole da autoconsciência e recuperação do funcionamento saudável. Ponderam que a “(...) experiência humana é composta por quatro aspectos, onde a consciência pode ser focalizada: consciência de sensações e ações, consciência de sentimentos, consciência de desejos e consciência de valores" (p. 192).

Aplicando esta asserção à vida familiar, supomos que os cuidadores ao transmitir aos filhos valores éticos, sobretudo o respeito à vida; a não violência; estimular a identificação e a alienação de experiências que favorecem a saúde e a vida coletiva pode interromper os ciclos de reprodução da violência psicológica.

Quando lidamos com a conscientização de valores e avaliações estamos tocando toda uma gama de julga- mentos e de contradições internas. Frequentemente os valores que o individuo constrói para si tem que ser reconstruídos quando contém material anacrônico (Polster \& Polster, 1979, p. 206).

Em relação à violência que ocorre nas famílias, as instituições públicas que determinam políticas e fornecem apontamentos para as intervenções na área tem produzido referências de uso amplo. A Organização Mundial da Saúde (OMS, 2002), define violência como o uso intencional da força ou poder em forma de ameaça efetivamente, contra si mesmo, contra outra pessoa, grupo ou comunidade, e que ocasiona ou tem grandes probabilidades de ocasionar lesão, morte, dano psíquico, alterações do desenvolvimento ou privações.

Ruiz \& Mattioli (2004) realizaram uma pesquisa sobre violência psicológica com integrantes do Conselho Tutelar da cidade de Presidente Prudente, no Estado de São Paulo, alertando que:

Para compreendê-la, é preciso que se dê atenção ao nível psicológico dos integrantes da família, à forma como se relacionam, aos confrontos por que passam e às soluções encontradas por eles, às disputas de poder, ao papel da autoridade, à vida privada, às questões religiosas e a sua história (pp. 121-122).

No que diz respeito à violência doméstica, para Silva \& Oliveira (2008), ela se dá como uma inversão da representação de uma $b o a^{3}$ família em nossa sociedade. Um ethos que deveria ser marcado por relações de afeto e confiança, passa a ser um espaço de relações abusivas, no qual os maus tratos são dirigidos contra crianças, adolescentes, mulheres e idosos.

Saliba et al. (2007, p. 473) afirmam que "a violência doméstica representa toda ação ou omissão que prejudique o bem-estar, a integridade física, psicológica ou a liberdade e o direito ao pleno desenvolvimento de um membro da família", se dando através de abusos nas relações de poder entre quaisquer membros da família, tenha laços consanguíneos ou não, ocorrendo na maior parte dos casos dentro do domicílio e se exercendo com maior frequência contra mulheres, crianças e idosos, quase sempre ocasionando danos diretos ou indiretos aos demais membros da família.

Milani e Loureiro (2008) chamam atenção para a dificuldade em caracterizar os diversos tipos de violência doméstica pela diversidade de manifestações possíveis que envolvem a vida privada. Silva, Coelho e Caponi (2007) afirmam que as demandas recebidas por programas governamentais e não-governamentais - de atendimento às vítimas de violência são em grande maioria feitas por mulheres que foram violentadas dentro de espaços domésticos, chegando ao índice de 98\% dos casos, sen-

Grifo nosso. 
do os agressores: maridos, amásios, amantes, namorados atuais, até mesmo, ex-namorados ou ex-cônjuges.

Barbosa e Pegoraro (2008) citando Gomes et al. (2002b) presentam alguns modelos explicativos para a origem da violência intrafamiliar contra crianças e adolescentes: modelo "Reprodutivo ou de Aprendizagem Social" em que há uma perpetuação dos maus tratos a partir de uma repetição de algum tipo de violência familiar sofrida na infância; padrão "Psicodinâmico" em que a violência é fruto de um desajuste familiar e psíquico, sendo explicada pela análise psicológica da personalidade do agressor; exemplo "Sociopsicológico" que articula e integra a questão macroestrutural e a psicológica, e o modelo "Ecológico" que considera a violência intrafamiliar como resultado de múltiplos fatores em interação.

Por sua vez, Marty (2006) afirma que a violência pode ter uma gênese psicopatológica, em particular a violência praticada na adolescência. Também faz uma distinção entre uma violência "comum" e "violência patológica”; e, tenta diferenciar outras modalidades: violência praticada e violência sofrida; violência autoagressiva e violência heteroagressiva. Neves e Romanelli (2006) alertam para a dificuldade de combater a violência doméstica/intrafamiliar, devido ser, em boa parte das ocorrências, de difícil identificação. Apesar do sofrimento da vítima, há dificuldades em buscar ajuda pelo temor as ameaças sofridas e/ou até mesmo pela falta de informações sobre a rede de serviços de apoio a vítimas de violência, entre outros fatores relacionados (Castro Filho \& Aoki, 2007).

Até aqui, apontamos que os textos usam o termo violência doméstica para se referir a todas as formas de violência praticada no ambiente familiar. Percebemos, ainda, que os autores, de modo geral, abordam mais especificamente a violência contra a mulher, perpetrada pelo seu parceiro íntimo; bem como um histórico de dominação masculina presente nas sociedades derivados de culturas patriarcais construídas sócio-historicamente (Porto, 2008). Outra conclusão que o campo mostra é que os conceitos de violência variam conforme a questão de interesse de estudo, por exemplo, uns pesquisam a violência relacionada à criança, outros ao adolescente, e alguns, ao adulto ou especificamente à mulher. Além disso, notamos que as descrições demonstram os pressupostos teóricos que o autor faz uso para realizar os seus estudos psicológicos, a exemplo, analíticos, gestálticos, fenomenológicos entre outros.

Ressaltamos que nos textos analisados a proposta de conceituar a violência torna-se tão abrangente que nos fez pensar que é oportuno tecer uma conceituação mais específica das violências que ocorrem nas famílias a fim de: a) facilitar o auto-reconhecimento por parte dos "atores” das relações violentas; b) apontar o cenário no qual a percebemos; e, c) elaborar intervenções que sejam efetivas e consigam abranger a complexidade existente nas interações familiares.
Assim, nosso posicionamento é criar o conceito de violência privada para descrever os atos e as palavras usadas pelos integrantes da família na prática das interações e relações em que as violências ocorrem (Pimentel, 2011). Esta alternativa intenta orientar nossas pesquisas e intervenções na clínica, oferecer clareza ao campo e superar o uso de diversas (e por vezes superpostas), taxonomias para as análises das violências que ocorrem nas famílias.

Violência privada é a prática costumeira que ocorre nas casas, com ou sem testemunhas ${ }^{4}$, entre sujeitos consanguíneos e não consanguíneos orientados pela imposição da autoridade visando à submissão e domínio da autonomia do outro em uma relação de poder (Pimentel, 2011).

A fundamentação da categoria violência privada é baseada nos seguintes argumentos:

a) O uso do signo "doméstico" não se coaduna com a presente realidade política e cultural relativa ao gênero feminino. Dizer que algo é doméstico é limitar ao âmbito da casa o cenário da inserção produtiva das mulheres, bem como, manter as ações violentas no enquadramento familiar. O contexto de expansão, inserção sócio-econômica e de participação pública e política das mulheres brancas, negras, amarelas e índias transcende o "lar";

b) Compreender a violência que ocorre nas e com as famílias por meio de análises dialéticas - significando desvelar as vinculações entre família e Estado no que concerne à viabilização por este último do bem-estar, trabalho, saúde, educação, lazer, etc. Os estudos e as ações organizadas em torno dos vários movimentos sociais e/ ou científicos em prol da cidadania das mulheres tem ampliado a compreensão da violência que ocorre nas casas;

c) Usar o conceito para fraturar a tese dos "segredos familiares" acerca das violências, o que pode contribuir para ampliar o reconhecimento das crianças concretas, meninos e meninas como sujeitos livres dos crivos opositores impostos pelas lentes de gênero; das mulheres; dos idosos e dos portadores de necessidades especiais;

d) Considerar a teoria da desconstrução dos signos violência e doméstica, em que desconstruir aponta as várias possibilidades da significação (Macedo \& Amaral, 2005).

\section{Considerações Finais}

O processo de instalação da violência privada tem início com o desentendimento do casal, se estende aos filhos e envolve a rede do entorno da família, vizinhos e trabalho. Quando o artifício se torna recur-

\footnotetext{
4 A experiência vivida é a testemunha da violência psicológica cujas marcas transcendem a expressão física. A ela damos crédito, valor e confiança. Tal ação respeita, sobretudo, a voz negada às crianças.
} 
sivo, a desqualificação, as exigências emocionais e as punições físicas repetidas são absorvidas pelos filhos/ sujeitos que recebem (de vários modos), e a experiência consciente da violência vivenciada pode transpor os limites da casa e ser reproduzida em meio público por adolescentes, envolvendo-os em roubos a mão armada e até assassinatos, ou submetendo-os ao exército do tráfico.

A violência psicológica, uma das consequências provenientes da violência privada, é uma forma de brutalidade que atinge o autoconceito, a autoimagem e a autoestima de alguém. É gerada em diversos contextos em que há desnutrição psicológica (Pimentel, 2005; 2008). Entendemos que sua instalação decorre da ação intencional e relacional dos sujeitos. Sua prática abre a possibilidade para a morte existencial, lenta e cotidiana das famílias e da sociabilidade pública. Atos violentos fazem surgir uma consciência da finitude dos valores éticos, interrompem a perspectiva do continuum do bem-comum, e instalam medos: da bala perdida, do sequestro relâmpago, do assalto pelo jovem que não completou 18 anos, da agressão do marido/companheiro/namorado, da humilhação, da negligência, etc.

$\mathrm{Na}$ lógica interna da violência psicológica estão estabelecidas práticas irracionais, pensamentos desprovidos de autocrítica, crítica social e de compreensão de campo; em consequência, os atores que a vivenciam não transparecem a consciência da existência do outro e/ou de si mesmo. Neste ponto de vista, o ressentimento e o desejo de vingança podem tornar-se o principal móvel da ação dos que são alvos da violência psicológica que consequentemente pode transpor a fronteira da violência física e em nome de supostas "reparações" da honra, da inoperância do Estado, chacinas podem ser cometidas por milícias ou por integrantes das famílias. Racismo, homofobia, violência de gênero, violência sexual, maus tratos contra idosos, crianças e adolescentes podem ser desdobramentos do exercício da opressão, do desconhecimento da existência do outro como alguém individualizado e diferente do eu, outro sujeito. É para este cenário que voltamos nossa preocupação acerca da consciência relacional sustentada pela ética de gêneros e do cuidado.

\section{Referências}

Barbosa, P. Z., \& Pegoraro, R. F. (2008). Violência Doméstica e Psicologia Hospitalar: Possibilidades de Atuação diante da Mãe que Agride. Saúde e Sociedade [online], 17 (30, 77-89).

Brad, H (1999). Pesquisa na internet. Rio de Janeiro: Campus.

Carvalho Neto, M. B., Alves, A. C. P., \& Baptista, M. Q. G. (2007). A "consciência" como um suposto antídoto para a violência. Revista Brasileira de Terapia Comportamental Cognitiva, 9 (1), 27-44
Castro Filho, J. M., \& Aoki, M. (2007). Caderno de Violência Doméstica e Sexual Contra Mulher. São Paulo: CODEPPSS, SMS.

Heidegger, Martín (1997) El Ser Y El Tiempo. México: Fondo de Cultura Económica.

Macedo, A. G., \& Amaral, A. L. (2005). Dicionário da Crítica Feminista. Porto: Edições Afrontamento.

Marty, F. (2006). Atenção a crianças e adolescentes vítimas de violência doméstica: Análise de um serviço. Ágora (Rio de Janeiro), 9 (1), 119-131.

Milani, R. G., \& Loureiro, S. R. (2008). Famílias e Violência Doméstica: Condições Psicossociais Pós Ações do Conselho Tutelar. Psicologia Ciência \& Profissão [online], 28 (1), 50-67.

Neves, A. S., \& Romanelli, G. (2006). A Violência Doméstica e os Desafios da Compreensão Interdisciplinar. Estudos de Psicologia (Campinas), 23 (3), 299-306.

Organização Mundial de Saúde (2002). Relatório Mundial sobre Violência e Saúde. Genebra: Organização Mundial de Saúde.

Perls, F. S. (1975). Yo, hambre y agresión: los comienzos de la terapia gestaltista. México: Fondo de Cultura Económica (Original publicado em 1942).

Perls, F. S., Hefferline, R., \& Goodman, P. (1997). Gestalt-terapia. São Paulo: Summus (Original publicado em 1951).

Pimentel, A. (2005). Nutrição Psicológica. São Paulo: Summus.

Pimentel, A. (2011). Violência Psicológica Conjugal: pesquisa e intervenção. São Paulo: Summus.

Pimentel, A., \& Araújo, L. S. (2009). Violência Sexual Intrafamiliar. Revista Paraense de Medicina, 20 (3), 39-42.

Pimentel. A., \& Moreira, A. C. (2008) (Orgs). Psicologia, instituição, cultura. Belém: Amazônia.

Polster. E., \& Polster, M. (1979). Gestalt-terapia integrada. Belo Horizonte: Interlivros.

Porto, M. (2008). Intervenção Psicológica em Abrigo para Mulheres em situação de violência: uma experiência. Psicologia: Teoria e Pesquisa, 24 (3), 369-374.

Ruiz, J. M., \& Mattioli, O. C. (2004). Violência psicológica e violência doméstica. Em M. F. Araújo \& O. C. Mattioli (Orgs), Gênero e Violência, (pp. 111-141). São Paulo: Arte \& Ciência.

Saliba, O., Garbin, C. A. S., Garbin, A. J. I., \& Dossi, A. P. (2007). Responsabilidade do Profissional de Saúde sobre a Notificação de Casos de Violência Doméstica. Revista de Saúde Pública [online], 41 (30), 472-477.

Salvador, A. D. (1978). Métodos e técnicas de pesquisa bibliográfica. Porto Alegre: Sulina.

Santos, A. A. S. \& Sougey, E. B. (2008). Tipos de Consciência: Implicações Psicopatológicas. Neurobiologia [online], 71 (1-2), 47-52. 
Silva, L. L., Coelho, E. B. S., \& Caponi, S. N. C. (2007). Violência silenciosa: violência psicológica como condição da violência física doméstica. Interface - Comunicação, Saúde, Educação (Botucatu), 11 (21), 93-103.

Silva, S. B., \& Oliveira, A. C. (2008). Violência Doméstica como Tema de Estudo em Programas de Pós-graduação no Estado do Rio de Janeiro. Revista Katálysis [online], 11 (2), 187-194.

Teixeira, J. F. (1997). A teoria da consciência de David Chalmers. Psicologia USP, 8 (2), 190-128.

Tourinho, C. D. C. (2002). O Problema da consciência no cenário contemporâneo da filosofia da mente: o debate entre John Searle e Daniel Dennett. Episteme (Porto Alegre), 14, 181-184.
Adelma Pimentel - Doutora em Psicologia Clínica pela Pontifícia Universidade Católica de São Paulo (PUC-SP), com Pós-Doutorado em Psicologia e Psicopatologia do Desenvolvimento na Universidade de Évora, Portugal. Atualmente é Professora Associada I na Universidade Federal do Pará (UFPA), Pesquisadora na Graduação e no Mestrado, e Diretora da Faculdade de Psicologia da UFPA. Coordenadora do NUFEN (Núcleo de Pesquisas Fenomenológicas) e Editora da Revista do NUFEN, Qualis B4. Endereço Institucional: Universidade Federal do Pará, Mestrado em Psicologia. Av. Augusto Correia, s/n (Guama). CEP 66075-110. Belém (PA).E-mail: adelmapi@ufpa.br

Paolo Mindello - Pesquisador da Iniciação Científica, Graduando do Curso de Psicologia da Universidade Federal do Pará.

Recebido em 10.07.11

Primeira Decisão Editorial em 12.11.11

Aceito em 04.03.12 